ANUARIo DE Estudios MEDIEVALES 48/2, julio-diciembre de 2018, pp. 587-614

ISSN 0066-5061

https://doi.org/10.3989/aem.2018.48.2.02

\title{
EL CAPÍTOL CATEDRALICI DE MALLORCA A LA SEGONA MEITAT DEL SEGLE XV (1450-1495)*
}

\author{
THE CATHEDRAL CHAPTER OF MAJORCA \\ IN THE LATER FIFTEENTH CENTURY (1450-1495)
}

\author{
Albert CASSANYES RoIG \\ Universitat de Lleida \\ http://orcid.org/0000-0002-6046-9201
}

\begin{abstract}
Resum: Tot i la importància del capítol catedralici de Mallorca durant la segona meitat del segle XV, la institució canonical no ha estat estudiada a fons. Aquest article presenta les bases sobre les quals construir una posterior investigació. En primer lloc, es fixa l'onomàstica dels canonges i els anys durant els quals ostentaren la prebenda, amb l'objectiu d'individualitzar-los i de determinar les persones que ocuparen les dignitats catedralícies i altres oficis a fora de la Seu. Tot seguit s'ofereixen algunes dades referents a les relacions familiars, fonamentals per explicar l'accés a les prebendes de certes persones, puix el nepotisme era molt habitual. En tercer lloc, els estudis universitaris també constituïen un factor determinant en el nomenament de canonges, i la normativa n'afavoria la formació. Finalment, les conclusions permeten delinear uns primers elements per a una prosopografia dels canonges de Mallorca al final de l'Edat Mitjana.
\end{abstract}

Paraules clau: capítol catedralici; dignitats catedralícies; estudis universitaris; Mallorca; nepotisme; prebendes eclesiàstiques.

Abstract: Despite the importance of the Majorcan cathedral chapter during the second half of the fifteenth century, the canonical institution has not yet been fully studied. This paper offers a basis upon which to build subsequent research. Firstly, it determines the canons' personal names and the period during which they occupied their prebends, with the objective of identifying them as well as the cathedral dignitaries and other office holders outside the see itself. Next, it offers some data about family relationships, which is fundamental for explaining the access certain people had to prebends, because nepotism was very common. Third, it will be shown that university degrees constituted a decisive factor in the appointment of canons. Finally, the conclusions allow us to outline the first elements for a prosopography of the canons of Majorca at the end of the Middle Ages.

Keywords: cathedral chapter; ecclesiastical dignitaries; university degrees; Majorca; nepotism; ecclesiastical prebends.

\section{SUMARI}

1. Introducció.- 2. Els canonges de Mallorca.-3. Les dignitats catedralícies.-4. Acumulació d'oficis, beneficis i prebendes.- 5. Els orígens familiars dels canonges.- 6. La formació dels canonges mallorquins.- 7 . Conclusions.- 8. Bibliografia citada.

\footnotetext{
* Article elaborat amb el suport de la Secretaria d'Universitats i Recerca del Departament d'Economia i Coneixement de la Generalitat de Catalunya. Aquest article s'emmarca en el projecte "Expressivitat, sentiment i emoció (segles XIIXV)" (HAR2016-75028-P), finançat pel Ministeri d'Economia i Competitivitat.

Cómo citar este artículo: Cassanyes Roig, Albert (2018), El capítol catedralici de Mallorca a la segona meitat del segle XV (1450-1495), “Anuario de Estudios Medievales" 48/2, pp. 587-614. https://doi.org/10.3989/aem.2018.48.2.02

Copyright: (c) 2018 CSIC. This is an open-access article distributed under the terms of the Creative Commons Attribution 4.0 International (CC BY 4.0) License.
} 


\section{INTRODUCCIÓ ${ }^{1}$}

Els canonges de la Seu de Mallorca durant l'Edat Mitjana no han gaudit d'un interès especial per part dels historiadors ni han estat estudiats de forma conjunta, fenomen que sí s'ha donat en altres diòcesis dels regnes hispànics ${ }^{2}$. En canvi, sí que han cridat l'atenció de determinats historiadors alguns canonges a títol individual, sobretot prebendats de la segona meitat de la centúria. S'han de destacar molt especialment els estudis de Maria Barceló i Gabriel Ensenyat, en el marc d'una investigació més ampla dedicada a la recepció de l'humanisme a Mallorca ${ }^{3}$. Per tant, tot i les valuoses aportacions realitzades fins a aquest moment, encara manca l'exercici de fixar la nòmina dels canonges que configuraren el capítol catedralici mallorquí en el període del trànsit del món medieval a la modernitat ${ }^{4}$.

Establir l'onomàstica dels canonges del segle XV, així com oferir-ne una brevíssima semblança biogràfica i una certa aproximació prosopogràifica, és una tasca que obliga a dur a terme una recerca entre diverses sèries documentals de l'Arxiu Capitular de Mallorca -institució fonamental per a l'estudi del capítol-, a causa, sobretot, de les llacunes que s'hi localitzen. Les actes capitulars, que constituirien la font natural per determinar el nom i les accions dels canonges, presenten un buit de trenta-tres anys -això és, una tercera part

\footnotetext{
${ }^{1}$ Abreviatures usades: $\mathrm{ACA}=$ Arxiu de la Corona d'Aragó; $\mathrm{ACL}=$ Arxiu Capitular de Lleida; $\mathrm{ACM}=$ Arxiu Capitular de Mallorca; $\mathrm{BMM}=$ Biblioteca del Monestir de Montserrat.

${ }^{2}$ Manquen estudis sobre els capítols catedralicis de la Corona d'Aragó. En tot cas, cal destacar la tesi doctoral de Munsuri 2006 i mencionar una certa referència a Sureda 2009. En canvi, els capítols castellans són més ben coneguts. Entre els estudis més generals, es poden destacar els de Sánchez 1976, Olivares 1997, Sanz 2000, Fernández 2003 o Luis 2004. Una menció especial mereix la tesi doctoral de Lop 2001, que analitza el capítol de Toledo al llarg de tota l'Edat Mitjana. També els capítols com a institucions de poder han comptat amb treballs, com Pérez, González 1993 o Vigil 2011. Bona part d'aquest poder es materialitzava en la concessió de beneficis, un fenomen que també ha estat estudiat de forma bastant ampla en els regnes hispànics, per exemple, per Santamaría 1990; Guijarro 2008; Agúndez 2014. El rol econòmic dels capítols, per la seva banda, ha estat posat en relleu per investigacions com les de Santamaría 1982, 1985. Un estat general de la qüestió, tot i que ja antic, és Lop 2003.

${ }^{3}$ La bibliografia al respecte és bastant ampla, ja que ha estat un tema freqüentment tractat per Maria Barceló i Gabriel Ensenyat (Barceló, Ensenyat 1996, 2000, 2010, per citar-ne alguns). La seva darrera aportació conjunta (2013) presenta una dotzena de biografies de canonges vinculats a l'humanisme i constitueix una primera i important aproximació prosopogràfica a part del capítol. Per altra banda, també s'han d'esmentar algunes aportacions en solitari d'Ensenyat 2012.

${ }^{4}$ A nivell europeu s'han desenvolupat alguns programes de recerca encaminats a establir la nòmina de bisbes $\mathrm{i}$ canonges i oferir-ne una prosopografia. Bona part d'aquests estan dedicats als eclesiàstics medievals, com puguin ser els Fasti ecclesiae Portugaliae per al Portugal del 1071 al 1325, els Fasti ecclesiae Gallicanae per a la França del 1200 al 1500, els Fasti ecclesiae Anglicanae per a Anglaterra i Gal-les entre 1300 i 1541, o els cinc volums dels Fasti ecclesiae Hibernica, per a Irlanda. Malauradament, no hi ha cap projecte similar per a les catedrals de les corones de Castella i d'Aragó.
} 
del segle-, entre 1433 i 1466. Part d'aquesta llacuna es pot compensar amb els llibres de la Mensa Capitular, ja que, en aquesta darrera sèrie, hi apareixen els noms dels canonges i les pensions canonicals percebudes durant un any. Això no obstant, també hi ha un buit important entre els anys 1430 i 1450, pel que s'ha de comptabilitzar un salt temporal de vint anys -en aquesta ocasió, "només" una cinquena part del segle-. A aquest bot també s'hi ha d'afegir una llacuna bastant important entre els anys 1494 i 1504; entre aquestes dues dates, sols es conserva el llibre corresponent a l'any 1499, el que suposa un tall destacable en la continuïtat de la sèrie. El Llibre de Possessoris de dignitats, canonicats, succentoria i pabordies de l'església de Mallorca ${ }^{5}$, que tant ha facilitat la feina dels historiadors que s'aproximen a l'estudi del capítol mallorquí de les edats moderna i contemporània, tampoc no és una font determinant per al període medieval. És cert que la relació de prebendats comença, precisament, en el segle $\mathrm{XV}$, però no ho fa de forma contínua fins a les seves darreres dècades $-\mathrm{O}$ inicis del XVI-, de manera que no tots els canonges de la centúria hi apareixen referits i, en ocasions, és possible trobar-hi errades, ja que la compilació no és pas contemporània. En qualsevol cas, la combinació d'aquestes tres sèries documentals permet la identificació dels canonges, primera passa fonamental a l'hora d'aprofundir en la seva vida com a individus, però també en el funcionament del capítol com a institució col·legiada.

El present article cerca d'aproximar-se al capítol de Mallorca durant la segona meitat del segle XV. Entre els seus objectius contempla, en primer lloc, l'establiment del nom dels prebendats que ostentaren una canongia entre els anys 1450 i 1495, així com el d'alguns dels oficis catedralicis més importants. A més, se cercarà d'establir les relacions familiars i de parentiu que pogués haver-hi entre els canonges i determinar la formació que els prebendats haguessin pogut assolir tant abans d'accedir al canonicat com durant l'ostentació d'aquest. L'objectiu final de tot plegat és identificar els canonges de Mallorca durant la segona meitat del segle XV i aproximar-se al sistema d'accés a les prebendes en aquesta catedral.

\section{Els CANONGES DE MALLORCA}

El capítol catedralici de Mallorca estava format per vint-i-dos canonges, nombre que havia estat fixat de forma definitiva el $1338^{6}$. A més de les canongies, el primer bisbe de Mallorca, Ramon de Torrella, havia erigit cinc

\footnotetext{
${ }^{5} \mathrm{ACM}, 15576$.

${ }^{6}$ Originàriament, el capítol de Mallorca s'havia fundat amb dotze canonges, que s'ampliaren a divuit el 1313 i a vint-i-dos el 1338. Villanueva 1851, pp. 83-84.
} 
dignitats capitulars -ardiaca, sagristà, cabiscol, succentor i sotsagristà- que no necessàriament havien de recaure en un canonge, tot i que, per norma general, eren ostentades per aquests alts prebendats. També es crearen altres oficis -concretament, quatre domers, un diaca, un sotsdiaca i un mestre de gramàtica-, les rendes dels quals eren abonades per la Mensa Capitular ${ }^{7}$. Finalment, el 1299 es va erigir el deganat, que va percebre les rendes de l'extinta dignitat de sotsacristà ${ }^{8}$. D'aquesta manera, des de principis del segle XIV, el capítol va quedar configurat en la forma en què va perdurar durant tota l'Edat Mitjana'.

El 1450 les vint-i-dues canongies estaven cobertes. A principis del mes d'abril ${ }^{10}$, el capítol estava integrat pels canonges Arnau de Marí i Santacília, ardiaca; Bernat Berard; Jordi Gual, degà; Joan Casas, cabiscol; Joan Umbert; Joan Salvà; Joan Borràs; Francesc Eiximenis; Dionís Sánchez Muñoz; Nicolau Muñoz, doctor en Drets ${ }^{11}$; Nicolau Montalt; Vicenç Martí; Francesc Sala; Pere Gual; Jaume Berard; Gaspar Albertí; Antoni Cerdà, cardenal; Francesc Rovira; Galceran Valleriola; Pere Pelegrí; Francesc Cruilles i Guillem Ponç de Fonollet. Això no obstant, al llarg del mig segle que abasta el present article, el capítol va haver d'anar cobrint les diferents vacants que es produïren arran de la defunció o resignació d'alguns dels seus membres.

Taula 1. Canonges de Mallorca entre 1450 i 1495.

Vicenç Martí (...-1452)

Francesc Cruïlles (...-1458)

Nicolau Montalt (...-23/5/1458)

Guillem Ponç de Fonollet (...-1459?)

Francesc Eiximenis (...-1460?)

Jaume Berard (..-1475?)

Joan Cases $(\ldots-19 / 1 / 1475)$

Francesc Sala $(\ldots-1481)$

Nicolau Muñoz (...-1488)

Pere Gual (...-1513?)

Gaspar Albertí (...-1515)

Francesc Sarovira (28/2/1407?-1451?)

Arnau de Marí i Santacília (1419?-15/5/1461)

Joan Umbert (22/11/1421-1463)

Bernat Berard (16/10/1423-1450)
Jordi Gual (25/4/1424-20/5/1472)

Joan Salvà (25/9/1427-11/3/1459)

Joan Borràs (3/1/1430-29/12/1464)

Galceran Valleriola (c. 1432-1451?)

Pere Pelegrí (10/7/1433-1451?)

Dionís Sánchez Muñoz (c. 1438-1463)

cardenal o senyor de Lleida [Antoni Cerdà] (1447-12/9/1459)

Gabriel Cerdà (15/8/1450-1491)

Miquel López (21/8/1451-c. 16/8/1504)

Bernat Oliver (9/11/1451-10/5/1467)

Jaume Ferrer (1453-1475)

Jaume Samasó (1453-1454?)

Francesc Torrella (1454-1455?)

Dionís Juan (1455-7/8/1464)

\footnotetext{
${ }^{7}$ Campaner 2007, p. 11.

${ }^{8}$ Serra 1774, pp. 21-22; Villanueva 1851, p. 87.

${ }^{9}$ No hi hagué canvis fins a la creació de la dignitat de tresorer el 1607 (ACM, 15576, f. 13r).

${ }^{10}$ Les anualitats dels llibres de la Mensa Capitular comencen el dia 1 d'abril i abasten fins al darrer dia de març de l'any següent.

${ }^{11} \mathrm{ACM}, 15576$, f. 31r.
} 
Martí Garcia (15/4/1458-1460?)

Bernat Rovira (26/8/1458-1460?)

Jofre Llançol (1459-1465)

Pere Bertran (23/5/1459-1486)

Jaume Oliver (11/7/1459-1460?)

Pedro Ferriz (1461-1466)

Rafel Patau (1461-1470)

Gabriel Rovira (1461-9/8/1476)

Antoni Juan (1461-c. 1495)

Gabriel Valls (5/11/1461-1488/1489)

Arnau de Marí (22/9/1463-1478?)

Esperandéu Espanyol (26/5/1465-1505)

Rafel Agustí (6/7/1465-31/5/1477)

Gabriel Burguet (19/9/1466-15/10/1507)

Joan Andreu Sorts (3/10/1467-31/1/1470)

Joan Soldevila (6/9/1468-1527)

Pere Lleopard? (1469?)

Francesc (Nicolau?) Rovira (20/7/146931/5/1474?)

Antoni Begur (31/1/1470-1483)

Nicolau Descatllar (17/10/1474-1479?)

Gaspar Llistó (20/10/1474-1502)

Bartomeu Sureda (1475-c. 1503)

Mateu Alber (21/11/1475-30/11/1488)

Gaspar Descatllar (1/2/1476-1493?)
Esteve Descós (10/8/1476-8/9/1479)

Antoni Busquets (16/12/1477-1490)

Miquel Oliva (1478?-1488)

Arnau de Santacília (1478?-1493?)

Francesc Milà (1479-1492)

Cristòfor de Marí (6/4/1481-17/3/1484) ${ }^{12}$

Jaume Miquel Armadans (15/7/1482-...)

Pere Montfort (1484?-1488?)

Andreu Mateu (1484-28/2/1493)

Miquel Lleonard Vidal (25/9/1486-1493?)

Pedro Díez Daux (1488-...)

Antoni Cerdà (28/2/1489-1503/1504)

Antoni Joan Busquets (1490-1522)

Pere Sard (1491-1501)

Jaume Jeroni Salom (1491-1525)

Gabriel Pons (1492-1538)

Lluís Guallats (19/8/1492-1497)

Joan Girona (28/2/1493-1495)

Joan d'Astorga (28/2/1493-1503)

Mateu Àlber (5/3/1493-1501)

Joan Mir (14/6/1493-...)

Com es pot veure en la taula, durant la segona meitat del segle XV el capítol de Mallorca comptà amb un total de setanta-quatre canonges que es varen anar succeint al llarg dels quaranta-cinc anys del període estudiat. D'aquests només va haver-n'hi dos que ostentessin la prebenda durant aquestes quatre dècades i mitja: els canonges Pere Gual i Gaspar Albertí13. Com en tots els càrrecs vitalicis, no hi ha un paràmetre temporal comú, de manera que la durada de la possessió de la canongia depenia de nombrosos factors, principalment dels anys de vida de cada titular, però també de les estratègies familiars que pogués haver-hi darrere de la gestió de la prebenda.

${ }^{12}$ El Llibre de Possessoris indica que "Als 6 Abril 1481. Posesió (sic.) al Ylle. Sr. Mº . Cristòfol de Marí del canonicat vacant per renunciació del Ylle. Sr. Moson Borge”. (ACM, 15576, f. 76r). S'ignora qui va ser aquest Borja que ostentà la canongia a Mallorca, si bé la seva presència no seria estranya, atenent que Roderic de Borja -futur Alexandre VI- en fou bisbe entre 1489 i 1492. Mateu 1985, pp. 175-183.

13 Gaspar Albertí va ser l'oncle del canonge i inquisidor mallorquí i bisbe de Patti Arnau Albertí, a qui va afavorir en tot moment. Quiroga 2009, p. 60; Barceló, Ensenyat 2013, pp. 117-119. 
La forma més comuna d'accedir a una canongia era l'elecció. En aquest cas, la tria del nou canonge corresponia al capítol, sempre amb la participació del bisbe ${ }^{14}$. En aquest punt, entraven en joc els possibles clergues en expectativa, això és persones que esperaven la formació d'una vacant per cobrir-la fent ús d'una gràcia especial concedida pel papa. Tot i que aquest sistema havia estat molt criticat, sobretot després del Cisma d'Occident -els diversos pretendents havien abusat d'aquest procediment per concedir beneficis i prebendes eclesiàstics i, d'aquesta manera, guanyar-se noves lleialtats-, i que el seu ús havia estat desaconsellat, els pontífexs continuaren utilitzant-lo, malgrat que de manera més controlada que en el passat. Per altra banda, no s'exigia que els aspirants a la canongia fossin preveres, sinó que també podien ser-hi admesos diaques i sotsdiaques. Això no obstant, des de Mallorca es va promoure que només poguessin pretendre una canongia els membres de famílies nobles o els graduats universitaris en qualsevol facultat, per tal de millorar l'estat financer de la institució. Tant els papes Martí V com Pius II confirmaren aquesta disposició $^{15}$.

A causa del caràcter vitalici dels canonicats, la major part de les vacants només es produïa per mort del canonge que l'ostentava fins aleshores. Les resignacions, per la seva banda, varen ser més escasses, tot i que se'n troben algunes. També es documenten algunes pèrdues de prebenda per promoció a un càrrec superior. Per exemple, Arnau de Marí i Santacília abandonà la canongia i l'ardiaconat en accedir al bisbat de Mallorca. També Pedro Ferriz actuà igual en ser promocionat a la càtedra episcopal de Tarassona; ara bé, malgrat que el seu nomenament tingué lloc el dia 1 d'octubre de $1464^{16}$, continuà percebent la porciócanonical fins al $1466^{17}$. Finalment, tambées documenten alguns casos de permutes, això és intercanvis entre dos càrrecs eclesiàstics. La primera permuta de la qual es té constància es va dur a terme l'agost de 1476, quan el canonge Gabriel Rovira va intercanviar la seva prebenda amb Esteve Descós ${ }^{18}$. La segona permuta tingué lloc el novembre de 1488 a Roma ${ }^{19}$, i hi prengueren part el canonge Mateu Àlber i

\footnotetext{
${ }^{14}$ Vegeu un context hispànic d'aquesta qüestió a Lop 2001, pp. 344-356.

${ }^{15}$ Xamena, Riera 1986, p. 82. Una disposició similar va ser aprovada a la diòcesi de Lleida durant el bisbat d'Antoni Cerdà, que era, al mateix temps, canonge de Mallorca (ACL, AC_0050, ff. 50r-v.). És possible que Cerdà desitgés instaurar en la seva diòcesi la mateixa norma que estava vigent a l'illa.

${ }^{16}$ Eubel 1914, p. 251.

${ }^{17}$ ACM, 2770, f. 36v.

${ }^{18}$ ACM, 2780, f. 47r.

${ }^{19}$ ACM, 2792, sf.
} 
Antoni Cerdà ${ }^{20}$. No es coneix per quin càrrec va permutar Àlber la canongia mallorquina. En tot cas, es poden descobrir interessos familiars al darrere d'aquest intercanvi de prebendes, puix Antoni Cerdà estava emparentat amb Mateu Àlber, que havia accedit al canonicat gràcies a la influència del seu oncle, el ja canonge Gabriel Cerdà ${ }^{21}$. Sigui com sigui, Àlber tornà a obtenir una prebenda a Mallorca cinc anys més tard: els llibres de la Mensa Capitular indiquen que Antoni Cerdà estigué present a Mallorca entre el 1489 i el 1493; des d'aleshores, el nom de Cerdà apareix en la documentació, però sense que se'n doni cap altra dada. D'altra banda, Mateu Àlber desapareix dels llibres d'aquella sèrie després de la permuta, però se'l torna a esmentar com a canonge entre els anys 1493 i $1495^{22}$. Com que Cerdà i Àlber compareixen en els mateixos llibres de forma simultània, és evident que la permuta es va dur a terme i que Antoni Cerdà prengué possessió efectiva del canonicat que havia estat de Mateu Àlber. Aquest, per la seva part, tornà al capítol ostentant una nova canongia, ja que hagué de tornar a realitzar el ritual acostumat, a més d'abonar el pagament corresponent a la fàbrica de la catedral ${ }^{23}$.

\section{LES DIGNITATS CATEDRALÍCIES}

Com s'ha indicat, en el moment de la fundació del capítol catedralici de Mallorca cap al 1240, el bisbe Torrella va erigir també les cinc dignitats catedralícies. De forma habitual, aquestes varen recaure en canonges, tot i que no era imprescindible comptar amb aquesta prebenda per accedir-ne a una. De fet, com es veurà, varen ser nombrosos els clergues no-canonges que ostentaren una dignitat, tot i que les més importants -l'ardiaconat i el deganat- sí que varen ser sempre posseïdes per alts prebendats. Cal esmentar, però, que les dignitats catedralícies només participaven a les sessions capitulars si també ostentaven un canonicat ${ }^{24}$. A continuació es presentarà una nòmina dels di-

${ }^{20}$ No s'ha de confondre aquest Antoni Cerdà amb el cardenal Antoni Cerdà, que havia mort el 1459.

${ }^{21}$ ACM, 2769, f. 46v. Agraeixo a Antoni Mas i Forners que m'hagi proporcionat les dades referents als entroncaments genealògics entre els Cerdà i els Àlber, que formen part de la seva tesi doctoral en elaboració Colonització, feudalisme, canvi social i paisatgístic a Mallorca (segles XIII-XVII). Una aproximació a partir de l'estudi de l'antic terme de Santa Margalida.

${ }^{22}$ ACM, 2797, f. 31r; i ACM, 2798, sf. Mateu Àlber no va morir fins al 1501 (ACM, 01-10ACA-017, f. 76r).

${ }^{23}$ ACM, 01-10-ACA-016, f. 190r.

${ }^{24}$ Xamena, Riera 1986, p. 81. 
versos eclesiàstics -canonges o no- que se succeïren al capdavant de les cinc dignitats catedralícies:

- L'ardiaca. L'ardiaconat era la principal dignitat de l'església de Mallorca ${ }^{25}$ i, com a tal, el seu posseïdor apareix sempre en primer lloc tant en les actes capitulars com en els llibres de la Mensa Capitular. La catedral comptava amb un únic ardiaca, a diferència d'altres diòcesis en les quals els ardiaques gestionaven els diversos ardiaconats en què estaven dividides territorialment, com fou el cas de Lleida ${ }^{26}$ o Àvila ${ }^{27}$. Des de mitjan segle XV era ardiaca de Mallorca el canonge Arnau de Marí i Santacília. El 1461 va ser elegit bisbe de Mallorca, el que l'obligà a abandonar la dignitat. Aquesta vacant va ser ocupada aleshores pel canonge Pere Gual, que era doctor en ambdós Drets ${ }^{28}$. Gual va ostentar la dignitat fins a principis del segle XVI.

- El sagristà. Aquesta dignitat custodiava els ornaments sagrats i vigilava el personal auxiliar de la catedral. El 1453 va ser designat sagristà de Mallorca el canonge Gabriel Cerdà, que va ostentar la dignitat catedralícia fins a la seva mort, esdevinguda el 1491, de manera que exercí aquest càrrec durant gairebé quaranta anys ${ }^{29}$. Tot i la defunció del canonge el 1491, sembla que la dignitat vacant no va ser coberta fins tres anys més tard, cap al mes d'abril de 1494. Aquell any va prendre'n possessió Jofré de Borja, fill de Roderic de Borja, aleshores bisbe de Mallorca. Jofré de Borja, però, no va ocupar massa temps la dignitat, ja que la va resignar mig any més tard; el 8 de novembre de 1494 el canonge Francesc Grasset, graduat en estudis jurídics, va prendre possessió del càrrec. Grasset va morir a Roma el 5 d'agost de 1499, i va ser-ne successor el canonge mallorquí Arnau de Santacília, que va prendre possessió de la dignitat l'any $1500^{30}$.

- El cabiscol o precentor. La dignitat de cabiscol era l'encarregada de dirigir el cant en el cor de la catedral i, en general, de tenir cura de

\footnotetext{
${ }^{25}$ Els ardiaques havien estat els principals auxiliars dels bisbes, però els capítols catedralicis els havien desplaçat $\mathrm{i}$, a la pràctica, el degà s'havia constituït com la principal dignitat catedralícia. Lop 2001, pp. 282-285. A Mallorca, en canvi, l'ardiaca pogué conservar bona part de la seva posició honorífica.

${ }^{26}$ Bolòs, Piqué 2008, pp. 123-126.

${ }^{27}$ Luis 2004, p. 354.

${ }^{28}$ Serra 1815, p. 214.

${ }^{29}$ El Llibre de Possessoris de la catedral de Mallorca indica que Cerdà ja era sagristà el 1450 (ACM, 15576, f. 4r).

${ }^{30} \mathrm{ACM}, 15576$, f. $4 \mathrm{r}$.
} 
la litúrgia. A més, també tenia competències en la formació dels escolans i en la supervisió de l'escola catedralícia. Des de mitjan segle XV va ser cabiscol de la Seu de Mallorca el canonge Joan Cases. Va ocupar el càrrec fins el dia 19 de gener de 1475. No es pot assegurar qui va ser-ne el successor, però és probable que fos Nicolau Descatllar, antecessor en la dignitat de Joan de Borja, que va ser nomenat cabiscol el 1478 arran de la vacant produïda per la mort de Descatllar estant a Roma. Joan de Borja va resignar-la el 1486 en Cèsar Borja, que en prengué possessió el 9 de juny d'aquell any i que va ostentar-la fins al 1505, quan també la resignà, en aquest cas en favor del canonge Llorenç de Santacília ${ }^{31}$.

- El degà. Tot i la importància del deganat ${ }^{32}$, aquesta dignitat va ser la darrera que es va fundar, ja que la seva creació no va tenir lloc fins al 25 de desembre de $1299^{33}$. Les seves funcions eren variades i comprenien la custòdia dels béns necessaris per als oficis divins, la vigilància que els capellans celebressin les misses corresponents a la catedral, i vetllar pel compliment dels estatuts capitulars o la correcció i composició dels llibres del capítol. A més, havia de tractar habitualment amb el bisbe i transmetre-li totes les faltes que detectés ${ }^{34}$. El deganat duia aparellat també una coadjutoria amb un valor de seixanta lliures, el que constitueix una evidència de la importància del càrrec, sobretot si es té en compte que ni l'ardiaca ni el sagristà percebien cap quantitat afegida a la seva dignitat de part de la Mensa Capitular. El 1450 era degà de Mallorca el canonge Bernat Berard ${ }^{35}$. Aquest va morir aquell mateix any -o poc abans- $\mathrm{i}$ va ser succeït per Jordi Gual, que ostentà el deganat fins que va morir el 20 de maig de 1472. Aleshores, la dignitat va recaure en Bartomeu Sureda ${ }^{36}$, que va ostentar-la fins al seu òbit, ocorregut el $1507^{37}$.

${ }^{31} \mathrm{ACM}, 15576$, f. $10 \mathrm{r}$.

${ }^{32}$ La seva precedència era entre el sagristà i el cabiscol. Serra 1774, p. 21.

${ }^{33}$ Villanueva 1851, p. 87.

${ }^{34}$ Serra 1774, p. 21 . Vegeu també, malgrat les diferències, Lop 2001, pp. 269-274.

${ }^{35}$ ACM, 01-10-ACA-014, f. 1r.

${ }^{36}$ Bonaventura Serra esmenta Bartomeu Sureda i Santmartí, fill de Salvador Sureda i Puigdorfila i de Magdalena Santmartí. Tot i això, no es tracta del mateix canonge, ja que Bartomeu Sureda i Santmartí viuria entre la segona meitat del segle XIV i la primera del XV. Serra 1815, pp. 240-241.

${ }^{37}$ El Llibre de Possessoris de la catedral de Mallorca indica que "En lo Llibre vell de la Fàbrica cart. 15, p. 2, consta de lo següent: 'Ytem deu lo Honor Miser Bartomeu Sureda Degà y canonge de Mallorca per la annata del Deganat, lo qual ha obtès per cambi amb $\mathbf{M}^{\circ}$. Joan de Borge taxada segons la reducta etcètera"” (ACM, 15576, f. 7r). És possible que es tracti d'una 
- El succentor o sotscabiscol. El succentor era un ofici que auxiliava el cabiscol en l'exercici de les funcions corals. La succentoria de la Seu de Mallorca comptà amb sis titulars durant la segona meitat del segle XV. El primer succentor que es té documentat és Dionís Sánchez Muñoz, que va morir el $1463^{38}$. La vacant va ser ocupada per mestre Heredia. Tot i això, Heredia no estigué massa temps al capdavant de la succentoria, ja que el 1467 va ser concedida a mestre Lleopard ${ }^{39}$. Aquest va permutar-la amb Miquel Salvador, tot i que no s'especifica l'any en què va tenir lloc aquesta permuta. En tot cas, Miquel Salvador va tornar a permutar la succentoria el 3 de gener de 1493 amb misser Estrada, que la va regir durant dos anys, ja que va morir el 1495. Aleshores va accedir al càrrec Pedro García de Atienza. Això no obstant, la Cúria Romana va intervenir i disposà que la succentoria de Mallorca fos concedida al cardenal Francesc de Borja, ja bisbe de Tiano. Com que Borja no es trobava a l'illa, el 16 de març de 1496 va prendre possessió de la succentoria el seu procurador, el canonge Esperandéu Espanyol. Francesc de Borja va ser succentor de Mallorca fins que renuncià al càrrec el $1505^{40}$. Com es pot observar, dels sis succentors documentats en el període estudiat, només un d'ells era canonge -Dionís Sánchez Muñoz, que exerciria l'ofici sota la direcció del cabiscol Joan Cases-, mentre els altres eren eclesiàstics d'altres nivells, fins i tot un cardenal. Per altra banda, tot i el seu origen com a dignitat catedralícia des de la fundació del capítol, la succentoria no apareix recollida en els llibres de la Mensa Capitular, mentre sí que s'hi apunten les altres dignitats -ardiaca, sagristà, cabiscol i degà-. Això permet sospitar que la succentoria havia deixat de ser considerada una dignitat eclesiàstica a mitjans del segle XV. De fet, Rosselló Lliteras afirma que el succentor no podia ser un canonge -a diferència de les altres dignitats-, malgrat ostentar les insígnies canonicals ${ }^{41}$.

confusió, perquè Joan de Borja va ser cabiscol entre els anys 1478 i 1486, càrrec del qual resignà en favor de César Borja (ACM, 15576, f. 10r). En canvi, no hi ha notícia de cap membre de la família Borja ostentant el deganat.

${ }^{38} \mathrm{ACM}, 2768$, f. 38v.

${ }^{39}$ Així apareix referida aquesta successió en el Llibre de Possessoris de Mallorca: "y en 1467, poch después del dit Eredia, posehía lo dit sucentorat lo Ylle. Sr. Mํ. Laopard" (ACM, 15576, f. 82r).

${ }^{40}$ ACM, 15576, f. 82r.

${ }^{41}$ Rosselló Lliteras 1978, p. 194. A més, en altres diòcesis el succentor és un porcioner. Lop 2001, pp. 301 i 320-321. 


\section{ACUMULACIÓ D’OFICIS, BENEFICIS I PREBENDES}

Un dels fenòmens més destacats de l'església medieval era la tendència a l'acumulació de càrrecs i prebendes per part dels seus membres ${ }^{42}$. L'objectiu final d'aquesta pràctica era tant l'increment de la influència i del prestigi social com la percepció del major nombre possible de rendes, el que es podia traduir, al seu torn, en un augment del patrimoni familiar ${ }^{43}$. Alguns canonges -especialment aquells que comptaven amb més influència- pogueren obtenir dignitats dins la mateixa catedral de Mallorca, com s'ha pogut observar en l'apartat precedent. Altres prebendats, per la seva part, també ostentaren oficis catedralicis diferents de les dignitats, especialment les pabordies o prepositures. Finalment, alguns canonges compatibilitzaren la seva prebenda canonical amb altres càrrecs o responsabilitats a fora de la Seu o, fins i tot, de l'illa. Al llarg de les següents pàgines es presentaran diversos casos concrets d'oficis, beneficis i prebendes que els canonges de Mallorca ostentaren al mateix temps que els seus respectius canonicats.

Un dels oficis més interessants per als canonges eren les pabordies o prepositures, llurs titulars -els pabordes o prepòsits- eren els responsables de les rendes capitulars. En un primer moment, només se n'havien fundades dues, una de les quals administrava les rendes de la meitat episcopal, i l'altra les de la meitat capitular. Durant el pontificat del bisbe Ponç de Jardí (1238-1302), però, les dues pabordies es dividiren en dues més, donant lloc a un total de quatre ${ }^{44}$. Alguns canonges aconseguiren ostentar una de les quatre prepositures de la Seu de Mallorca, els rèdits de les quals els permetia completar la porció canonical, ja que percebien d'aquelles un total de setantacinc lliures anuals. Tot $\mathrm{i}$ això, la pabordia no era un càrrec reservat $\mathrm{i}, \mathrm{com}$ es presentarà a continuació, altres clergues no-prebendats també pogueren accedir-hi.

Dues de les pabordies estaven vinculades al bisbe de Mallorca. La primera era la coneguda com a pabordia a la part del cor del bisbe. El 1450 n’era paborde el canonge Gabriel Cerdà ${ }^{45}$. Després de la seva mort el 1491,

${ }^{42}$ L'acumulació de beneficis era una pràctica abusiva que anava en contra de l'esperada disciplina eclesiàstica. Tot i que el concili III del Laterà (1179) havia disposat la incompatibilitat de beneficis, les seves resolucions no varen ser observades, en part a causa de les dispenses $\mathrm{i}$ exempcions atorgades pels mateixos papes. Iglesias 2010, p. 308. També a nivell diocesà es podien prendre mesures encaminades a evitar o limitar l'acumulació de beneficis i prebendes. Lop 2001, pp. 161-162 i 377-378; 2014, pp. 148-150.

${ }^{43}$ Perfectament documentat, en el cas dels Cerdà, a Mas 2000,pp. 441-442. Seria interessant continuar amb aquesta línia de recerca en referència a altres canonges i diòcesis.

${ }^{44}$ Dameto, Mut, Alemany 1841, p. 643; Serra 1815, p. 151.

${ }^{45}$ ACM, 2758, f. 59v. 
va ser proveïda en Antoni Francesc Bartomeu, que també ostentà el càrrec fins a la seva defunció cap a $1507^{46}$. La segona prepositura era la denominada pabordia a la part del bisbe. El primer paborde que es té documentat el 1450 és el canonge Francesc Rovira. Tot i això, el 20 de novembre del mateix any va prendre possessió de la pabordia el també canonge Francesc Sala. Tot i que Sala ostentà la canongia fins al 1481, el 7 de juny de 1451, només set mesos després d'haver-ne pres possessió, la pabordia passà a Jaume Samasó, que la posseí durant tres anys, ja que el 1454 el càrrec fou proveït en Francesc Torre$11 a^{47}$. El mandat de Torrella no va ser massa llarg, i el 1457 s'hi troba el canonge Dionís Juan com a prepòsit. Aquest regiria la pabordia fins a la seva mort, ocorreguda el 7 d'agost de 1464. Aleshores va passar a Mateu Falcó, rector de la parròquia de Sant Joan i el primer que no va compatibilitzar la pabordia amb una canongia. Sembla que Falcó ja en prengué possessió el 1464, tot i que és possible que no abonés els drets corresponents al seu possessori fins al $1470{ }^{48}$. El 1499 Mateu Falcó va voler afavorir l'accés del seu nebot Joan Falcó, doctor en ambdós Drets, a un ofici catedralici, de manera que va permutar o resignar la pabordia en favor d'aquest ${ }^{49}$.

Les dues prepositures capitulars, per la seva banda, estaven vinculades nominalment a la dignitat de l'ardiaca. Així doncs, hi havia, en primer lloc, la pabordia a la part de l'ardiaca. El 1450 n'era paborde Rafael Manera, que va ser succeït el 26 de setembre de 1475 per Bernat de Pacs. A la seva mort, ocorreguda el 1489, la prepositura va ser posseïda per Joan Marrades, que era doctor en ambdós Drets ${ }^{50}$. Deu anys més tard, el 1499, va accedir-hi el primer canonge en aquesta successió, Gabriel Pons, que també era doctor en ambdós Drets $^{51}$. En canvi, la darrera prepositura, la denominada pabordia a la part del cor de l'ardiaca, sí que va ser exercida majoritàriament per prebendats. El 1450 el càrrec era ostentat pel canonge Gaspar Albertí. Cap al 1470

${ }^{46}$ ACM, 15576, f. 85r.

${ }^{47} \mathrm{~S}$ 'ha de fer notar que Jaume Samasó és documentat com a canonge entre els anys $1453 \mathrm{i}$ 1454, mentre Francesc Torrella ostentaria un canonicat entre el 1454 i el 1455. Aquesta coincidència en la data de finalització $i$ inici de la canongia i de la prepositura permet sospitar una permuta de càrrecs. Tot $i$ això, la documentació no en fa cap menció.

${ }^{48}$ Així doncs, el Llibre de Possessoris indica que "En lo añy 1470 obtenia la dita Pabordia $\mathbf{M}^{\mathrm{o}}$. Mateu Falcó, Paborde y Rector de St. Juan de Sineu, com resulta del Llibre vell de la Fàbrica, f. 26, p. 2 y f. 27, a hont consta haver pagat dit añy per el posesori de dita Pabordia" (ACM, 15576, f. 88r).

${ }^{49}$ Joan Falcó va seguir el mateix exemple que el seu oncle i el 1505 resignà la pabordia en favor de Bartomeu Falcó. ACM, 15576, f. 88r.

${ }^{50}$ Aquesta successió és donada per ACM, 15576, f. 91r. En canvi, el llibre ACM, 2793, f. 29r, mostra que Pacs va ser succeït per Gabriel Pons ja el 1489, i no el 1499, com afirma el Llibre de Possessoris.

${ }^{51} \mathrm{ACM}, 15576$, f. 91r. 
hi accedí Antoni Busquets. Aquest va decidir permutar la pabordia amb la canongia que tenia Francesc (Nicolau) Rovira ${ }^{52}$. Antoni Busquets va prendre possessió del canonicat el 16 de desembre de $1474^{53}$, la mateixa data en la qual Rovira també hauria d'haver accedit a la prepositura. Això no obstant, sembla que aquest no va prendre'n possessió fins al 16 de desembre de $1477^{54}$. Uns quinze anys més tard, el 26 de desembre de 1493, Rovira tornà a permutar la pabordia, en aquesta ocasió amb Joan Borràs ${ }^{55}$. El 20 de març de 1499 Borràs va resignar-la en favor de Gil de Noverca, que l'ostentà fins a la seva mort, succeïda cap al $1512^{56}$.

La resta d'oficis catedralicis varen comptar amb una presència ínfima o nul-la dels canonges mallorquins. Una de les responsabilitats més importants eren les domeries, que havien estat erigides en el mateix moment en què s'havia estructurat l'església de Mallorca i s'havia fundat el capítol. Això no obstant, els canonges no podien exercir el càrrec de domer ${ }^{57}$. La Mensa Capitular també pagava els primatxers, els cantors principals del cor. Aquest ofici no va ser exercit a la Seu per cap canonge durant la segona meitat del segle $\mathrm{XV}$, tot i que Gabriel Valls i Antoni Busquets l'ostentaren amb anterioritat a l'obtenció del seu canonicat.

En canvi, fou habitual que els canonges també tinguessin responsabilitats a fora de la catedral. Una de les més frequients va ser la possessió d'una rectoria en una -o més d'una- parròquia, especialment de la Part Forana. Va ser el cas d'Esperandéu Espanyol, que va haver d'enfrontar-se a Gaspar de Santàngel, degà de Calataiud, per accedir a la rectoria de Manacor ${ }^{58}$. També el canonge Gabriel Pons, ja dins el segle XVI, va ostentar la de Felanitx, ja que es té notícia que exercia aquest càrrec parroquial el $1517^{59}$. Per la seva banda, Arnau de Santacília va ser rector de Selva i de la parròquia de Santa Eulàlia de la ciutat de Mallorca ${ }^{60}$. Evidentment, la

\footnotetext{
${ }^{52}$ El Llibre de Possessoris es refereix al canonge Francesc Rovira amb el nom de Nicolau.

${ }^{53} \mathrm{ACM}, 15576$, f. 94r.

${ }^{54}$ ACM, 2781, f. 31r. El Llibre de Possessoris no és clar en aquest sentit: dóna com a data del possessori de la pabordia el desembre de 1477, tot i que, en el cos del text, indica que Busquets prengué possessió de la seva canongia el 16 de desembre de 1474, "de què se collegeix que el posesoria de dita Pabordia també seria circa dit temps" (ACM, 15576, f. 94r). No es pot descartar que el compilador del Llibre de Possessoris cometés una errada de transcripció en la data del possessori de la canongia de Busquets, i que confongués la lectura de $1477 \mathrm{amb}$ 1474, sobretot si es té en compte que el dia i el mes dels possessoris coincideixen.

${ }^{55}$ No es té constància de quin càrrec permutà Joan Borràs per la pabordia.

${ }^{56}$ ACM, 15576, f. 94r.

${ }^{57}$ Mateu 1985, p. 149.

${ }^{58}$ Barceló, Ensenyat 2010, pp. 53-56.

${ }^{59}$ Serra 1815, p. 214.

${ }^{60}$ Barceló, Ensenyat 2013, p. 37.
} 
compatibilitat entre dos oficis eclesiàstics només era possible a través de la pràctica de l'absentisme ${ }^{61}$, de manera que el titular no residia a la rectoria corresponent, sinó que es limitava a governar-la a través d'un vicari i a percebre'n els rèdits que li pertocaven. En moltes ocasions el dret a abstenir-se era concedit pel papa mitjançant el denominat privilegi de fructibus in absentia, que havia de ser presentat davant l'autoritat eclesiàstica pertinent.

També es podien ostentar oficis a fora de Mallorca. L'exemple més destacat, en aquest sentit, és Antoni Cerdà, que, al mateix temps que era canonge de Mallorca, era bisbe de Lleida i cardenal i, de fet, residia habitualment a Roma. Igualment, el seu nebot Gabriel Cerdà era canonge en dues diòcesis diferents: Mallorca i Lleida. Aquest fet el va obligar a viatjar contínuament entre les dues seus ${ }^{62}$, tot i que es trobava majoritàriament a l'illa, ja que, al mateix temps que ostentava les prebendes, procurava augmentar el patrimoni familiar ${ }^{63}$. Vinculat també a Lleida va estar-hi el canonge Nicolau Muñoz, que fou durant un breu període vicari general de la diòcesi en nom del bisbe Cerdà ${ }^{64}$. Ara bé, la major part dels canonges que ostentaven dues prebendes en seus diferents compatibilitzava la canongia mallorquina amb una altra a la diòcesi de Barcelona. Un d'aquests va ser el canonge Joan Andreu Sorts, a qui ja es troba documentat com a prebendat barceloní el $1461^{65}$, sis anys abans de ser-li constituït el salari per la seva canongia de Mallorca. Sorts va ser un canonge absent, de manera que no se'l documenta a l'illa durant els dos anys i mig que ostentà el càrrec. Això no significa, però, que no treballés per a la diòcesi mallorquina, ja que apareix referit en ocasions com a procurador del capítol a la cort reial. En qualsevol cas, Sorts va resignar la seva canongia el $1470^{66}$, i la vacant va ser coberta per Antoni Begur.

Un cas especial d'un canonge de Mallorca que compatibilitzà la seva prebenda amb un càrrec a fora de l'illa fou el de Gabriel Valls. El canonge era, al mateix temps, succentor de la Capella Reial de Joan II. De fet, el monarca el va cridar en diverses ocasions a la cort barcelonina i era un destinatari freqüent de les missives reials. El 5 de febrer de 1466, Joan II va enviar una carta al capítol de Mallorca en la qual sol-licitava als canonges

\footnotetext{
${ }^{61}$ Vidal 1985, pp. 269-270.

${ }^{62}$ Cassanyes 2016.

${ }^{63}$ Mas 2000.

${ }^{64}$ ACL, AC, 0050, ff. $153 \mathrm{v}-155 \mathrm{r}$.

${ }^{65}$ Molina 1999, p. 35. Fins i tot apareix retratat en el retaule de Santa Tecla i Sant Sebastià que es conserva en la capella homònima, que li va ser atorgada el 1479. Borau 2003, p. 273.

${ }^{66} \mathrm{ACM}, 2774$, f. 32r.
} 
que autoritzessin Valls a viatjar a la cort per oficiar les misses corresponents al temps de Setmana Santa. Així mateix, demanava que el deixessin residir durant dos anys a la Ciutat Comtal. El capítol va accedir a la primera petició reial i donà llicència a Gabriel Valls per traslladar-se a Barcelona durant el temps pasqual. Però no va satisfer la segona pretensió del monarca. A tal efecte, el canonge Valls s'embarcà cap a la península el 16 de març de $1466^{67}$, però tornà a l'illa el 27 d'octubre següent, poc més de mig any després de la seva partida ${ }^{68}$.

Però els canonges de Mallorca no només tingueren rellevància dins la Corona d'Aragó, sinó també en les altes esferes de la Santa Seu. Ja s'ha comentat el cas d'Antoni Cerdà, que era cardenal al mateix temps que ostentava la prebenda mallorquina. Similar va ser el cas de Pedro Ferriz, que fou canonge de Mallorca entre els anys 1461 i 1466, tot i que mai residí a l'illa. De fet, Ferriz viuria a Roma, al servei dels cardenals Guillaume-Hugues d'Estaing i Pietro Barbo -futur Pau II, que el creà cardenal in pectore el 1467-, i seria auditor del tribunal de la Rota, referendari apostòlic, comissari a Lieja i llegat a Alemanya, entre molts d'altres càrrecs ${ }^{69}$. Ferriz ostentà la canongia mallorquina fins al moment de la seva promoció al bisbat de Tarassona el $1464^{70}$. De fet, els canonges que accedien a un bisbat solien abandonar la seva prebenda catedralícia, com va ser també el cas d'Arnau de Marí i Santacília. Això no obstant, també era possible obtenir una dispensa papal que permetés gaudir tant de la canongia com de la prelatura. N'és un exemple el ja esmentat Antoni Cerdà, que compatibilitzà la canongia de Mallorca amb l'arquebisbat de Messina, primer, i la mitra de Lleida a partir de 1449.

No es pot clausurar aquest apartat sense fer referència a la particularitat del canonge Pere Gual, ardiaca de la Seu mallorquina. Gual va ser també inquisidor de Mallorca entre els anys 1493 i 1495, això és en el moment inicial del tribunal del Sant Ofici a l'illa, instaurat en la seva forma moderna el 1488. Els inquisidors havien de comptar amb estudis de Dret i provenir de famílies gens sospitoses en l'àmbit genealògic, dos requisits que complia Pere Gual, doctor en ambdós Drets i pertanyent a un distingit llinatge noble de la ciutat de Mallorca que donaria encara altres canonges en el futur. Era habitual que, amb anterioritat al seu nomenament, els inquisidors ja comptessin amb una canongia, de la qual en continuaven percebent els fruits durant el seu mandat ${ }^{71}$.

\footnotetext{
${ }^{67} \mathrm{ACM}, 2770$, f. 35v.

${ }^{68} \mathrm{ACM}, 2771$, sf.

${ }^{69}$ Fuente 1863, pp. 229-233.

${ }^{70}$ ACM, 2770, f. 36v.

${ }^{71}$ Colom 1986, pp. 33-36; 1992.
} 


\section{ELS ORÍGENS FAMILIARS DELS CANONGES}

L'estudi del capítol catedralici de Mallorca, com el de qualsevol altra diòcesi medieval, obliga a dur a terme una aproximació a les nissagues a les quals pertanyien els canonges, ja que l'església era una de les col-locacions habituals dels fills segons de les principals famílies. L'interès d'aquestes en comptar amb un membre dins de la catedral en general, i en el capítol en particular, s'explica per les estratègies de promoció política, econòmica i social que els llinatges més benestants seguien en vistes a incrementar la seva influència en els diferents àmbits de les ciutats baixmedievals $i$ a augmentar el patrimoni propi ${ }^{72}$.

El cas de Gabriel Cerdà és un exemple paradigmàtic del que s'ha indicat. Per començar, és una mostra clara de la pràctica del nepotisme dins l'església, i no només pel que fa a Mallorca. El 15 d'agost de 1450 Gabriel Cerdà va prendre possessió de la canongia que havia quedat vacant en el capítol mallorquí per mort de Bernat Berard ${ }^{73}$. Gabriel Cerdà era nebot d'Antoni Cerdà, que, en aquell moment, era cardenal, bisbe de Lleida i canonge de la Seu de Mallorca ${ }^{74}$. És possible que el purpurat hagués facilitat al seu nebot l'obtenció de la canongia de Berard, de la mateixa manera que ho hauria fet a la diòcesi de Lleida, de la qual Antoni Cerdà n'era bisbe des d'abril de 1449 i Gabriel Cerdà canonge des del 17 de desembre del mateix any ${ }^{75}$. La importància que el nebot adquirí a les dues seus es fa palesa en el fet que va ser designat prepòsit del mes de maig de la catedral de Lleida ${ }^{76}$ i sagristà de la de Mallorca. Per altra banda, Gabriel Cerdà també va protagonitzar un procés d'increment patrimonial a la seva vila natal, Santa Margalida, utilitzant els recursos que obtingué de les diverses prebendes que ostentà al llarg dels seus quaranta anys de carrera eclesiàstica ${ }^{77}$.

El cas dels Cerdà no és l'únic que es registra. Segurament els canonges Jordi Gual i Pere Gual eren parents, membres d'una de les famílies més antigues de la noblesa mallorquina. Jordi Gual accedí a la prebenda el 25

\footnotetext{
${ }^{72}$ Mas 2000; Díaz 2009.

${ }^{73}$ ACM, 2758, f. 55v.

${ }^{74}$ No es pot precisar la data exacta en què Antoni Cerdà va ser nomenat canonge de Mallorca, però el 1450 ja ho era perquè apareix als llibres de la Mensa Capitular percebent tots els fruits de la seva prebenda (ACM, 2758, f. 58r).

${ }^{75} \mathrm{ACL}, \mathrm{AC} \_0049$, ff. 121v-122v. Tot i que no en va prendre possessió personalment fins dos anys més tard, el 20 de desembre de 1451 (ACL, AC_0050, f. 55v).

${ }^{76}$ ACL, AC_0049, f. 170r. La catedral de Lleida comptava amb set pabordies, que s'encarregaven dels pagaments de les rendes durant uns mesos determinats. Vegeu Terré, Baulies 1993, pp. 119-121.

${ }^{77}$ Mas 2000.
} 
d'abril de 1424. Pel que fa a Pere Gual, es desconeix quan va ser elegit, tot i que el 1450 ja figura com a canonge de Mallorca. Per tant, és molt probable que Jordi Gual afavorís l'accés a la canongia del seu parent, una pràctica que, per altra banda, no era gens estranya. En tot cas, Pere Gual fou nomenat ardiaca de Mallorca en substitució d'Arnau de Marí mentre Jordi Gual ostentava el deganat. Així doncs, els dos Gual regiren al mateix temps les dignitats més importants de l'església mallorquina durant un període d'onze anys, entre el nomenament de Pere Gual el 14 de maig de 1461 i la mort de Jordi Gual el 20 de maig de 1472. Això no obstant, Pere Gual continuà com a ardiaca fins a principis del segle XVI, de manera que també podria haver afavorit un altre parent, Miquel Gual, en la promoció a una canongia el $1499^{78}$.

De la mateixa manera, no es pot descartar tampoc un cas de nepotisme protagonitzat per la família Marí, una de les més importants de la noblesa mallorquina. El 1463 va morir Joan Umbert, i la canongia vacant va ser proveïda en Arnau de Marí, fill de Llorenç de Marí ${ }^{79}$. Aquest fet va coincidir amb l'episcopat del bisbe Arnau de Marí i Santacília ${ }^{80}$. És molt probable, per tant, que Arnau de Marí for parent del prelat homònim, que havia estat canonge i ardiaca de Mallorca fins a la seva promoció a la mitra el 1461, i que aquest hagués afavorit la seva elecció a la prebenda vacant. A més, s'ha de tenir en compte que Llorenç de Marí va ser jurat de l'any $1462^{81}$. Si bé no és possible identificar amb seguretat aquest jurat amb el pare del canonge Arnau de Marí, és molt probable que es tracti de la mateixa persona, atenent el fet que la documentació destaca aquesta filiació, un fet que no és massa comú en aquest tipus de fonts. De fet, la vinculació amb el bisbe de la diòcesi era una bona eina per obtenir una prebenda. A Mallorca s'hi troba el cas primerenc del canonge Dionís Sánchez Muñoz, prevere de València i nebot de Gil Sánchez Muñoz, antic antipapa Climent VIII d'Avinyó (1424-1429) i bisbe de Mallorca després de la seva renúncia a la tiara $(1429-1446)^{82}$. Aquesta acció s'ha d'inscriure en l'habitual pràctica del nepotisme, sobretot si es té en compte el fet que Dionís Sánchez Muñoz fou elegit per aclamació del capítol catedralici el 2 de setembre de 1431, només dos anys després del nomenament del seu oncle, i malgrat els drets que va presentar Antoni Riera per ser proveït de la canongia i succentoria que havien estat de Llorenç Serralli ${ }^{83}$.

\footnotetext{
${ }^{78}$ ACM, 01-10-ACA-017, ff. 27v-28r.

${ }^{79}$ ACM, 2779, f. 75v.

${ }^{80}$ Mateu 1985, pp. 145-152.

${ }^{81}$ Llompart 1975, pp. 212-213.

${ }^{82}$ Navarro, Villanueva 2006-2008, pp. 249-250.

${ }^{83}$ ACM, 01-10-ACA-014, ff. 1r-4r.
} 
Un altre cas particular és el dels Rovira, molt vinculats al papa Calixt III. Sota el pontificat del primer papa Borja, Bernat, Gabriel i Nicolau Rovira ostentaren importants càrrecs i obtingueren algunes prebendes que els permeteren promocionar en la seva carrera eclesiàstica. Dos d'aquests tres Rovira estigueren vinculats a Mallorca. Així doncs, el 1458 Bernat Rovira va aconseguir una canongia a la Seu de Mallorca, després d'haver-hi obtingut una expectativa i que el rei n'autoritzés la provisió ${ }^{84}$. Tot i això, Bernat Rovira només apareix documentat durant dues anualitats en els llibres de la Mensa Capitular, i sempre absent ${ }^{85}$, un fet, per altra banda, gens estrany atenent les seves responsabilitats a la Santa Seu i al tribunal de la Santa Rota. Curiosament, just després de la desaparició de Bernat Rovira dels registres hi apareix Gabriel Rovira, a qui s'havia concedit una expectativa a Girona o Barcelona. Aquesta es va veure ampliada després també a Mallorca ${ }^{86}$ i a València ${ }^{87}$. Gabriel Rovira no va estar mai a Mallorca durant els quinze anys documentats durant els quals va ostentar una canongia (1461-1476); de la mateixa manera que Bernat Rovira, els seus oficis a Roma -era governador de la fortalesa de Narni ${ }^{88}$ - l'obligaven a restar a la península Itàlica. No hi ha menció a cap resignació duta a terme per Bernat Rovira en favor de Gabriel Rovira, tot i que la coincidència de dates entre la sortida de Bernat i l'aparició de Gabriel en els llibres de la Mensa Capitular permeten hipotetitzar una resignació pactada, un fet que no és excepcional a les catedrals baixmedievals.

Per altra banda, també hi ha alguns Rovira que no semblen vinculats directament a la cort papal, però que és possible que aprofitessin la influència de Bernat i Gabriel Rovira. De fet, el 20 de juliol de 1467 va prendre possessió d'una canongia Francesc Rovira, que era nebot de misser Gabriel Rovira ${ }^{89}$, aleshores canonge de Mallorca. A diferència del seu oncle, Francesc Rovira sí que va estar present a l'illa fins al 16 de desembre de 1477, data en què va permutar la seva canongia per la pabordia que ostentava Antoni Busquets, com ja s'ha indicat abans. Amb anterioritat a aquest Francesc Rovira, però, es troba un canonge i prepòsit homònim, que va morir el 1450. No es pot descartar que aquest primer Francesc Rovira estigués emparentat d'alguna manera amb els altres membres d'aquest mateix llinatge, tot i que no hi ha cap prova documental que, ara per ara, pugui sustentar aquesta afirmació. Per la seva banda, Antoni Busquets, un cop obtinguda la prebenda que havia estat de Rovira el 1477, la va

\footnotetext{
${ }^{84}$ Rius 1927, pp. 291-292.

${ }^{85}$ ACM, 2764, f. 40r; ACM, 2765, f. 46r.

${ }^{86}$ Rius 1927, p. 292.

${ }^{87}$ ACL, P7_M1_P5_C06, sn. [Proceso de Gabriel Rovira apostólico 3-2-1458], f. 14v.

${ }^{88}$ Rius 1927, p. 292.

${ }^{89}$ ACM, 2781, f. 29r.
} 
ostentar durant tretze anys. El 1490, observant la ja esmentada pràctica habitual entre els canonges, la resignà en favor del seu nebot Antoni Joan Busquets ${ }^{90}$.

\section{LA FORMACIÓ DELS CANONGES MALLORQUINS}

Cada vegada més, l'església exigia que els seus membres, especialment els que ostentaven els alts càrrecs eclesiàstics, comptessin amb una formació adient que els fes idonis per a l'exercici de les seves funcions. De fet, aquesta qüestió havia estat tractada en el concili de Constança (1414-1418), i el papa Martí $\mathrm{V}$ va disposar que els bisbes i les altes dignitats catedralícies havien de posseir un grau universitari per poder accedir al lloc. A més, els clergues que haguessin obtingut un títol tindrien preferència a l'hora de la provisió de beneficis ${ }^{91}$. Per altra banda, des de la jerarquia eclesiàstica s'afavoria que els religiosos mallorquins comptessin amb estudis universitaris. El 1401 el papa Benet XIII d'Avinyó va manar que es dotessin cinc pensions de seixanta lliures cadascuna per sufragar les despeses de la formació dels eclesiàstics de l'illa ${ }^{92}$.

Els estudis que més sovint varen cursar els canonges de la catedral de Mallorca varen ser els que s'oferien a les facultats de Dret, en qualsevol de les seves dues branques: Civil o Canònic. És evident que els prebendats optaren, de forma majoritària, per l'estudi de Cànons, atès el seu caràcter eclesiàstic. Abunden els exemples de doctors en Cànons que exerciren les dignitats, les canongies i els oficis a la catedral de Mallorca: és el cas, per citar-ne alguns, de Bernat Berard ${ }^{93}$, de Gabriel Rovira ${ }^{94}$, d'Esperandéu Espanyol o de Joan de Soldevila ${ }^{95}$. Però, al mateix temps, eren també molts els que triaven cursar el grau en ambdós Drets -Civil i Canònic-, que concedia un gran prestigi al graduat ${ }^{96}$. Aquest va ser el cas, per exemple, de l'ardiaca Pere Gual, de Bartomeu Sureda, de Nicolau Muñoz i d'Arnau de Santacília, entre d'altres ${ }^{97}$.

L'Estudi General Lul-lià de Mallorca no es va fundar fins al $1483^{98}$, de manera que, al llarg de tota l'Edat Mitjana, els mallorquins que volgueren

${ }^{90}$ ACM, 15576, f. 73r.

${ }_{91}^{1}$ Álvarez 1984, pp. 297-300.

${ }^{92}$ Xamena, Riera 1986, p. 86.

${ }^{93}$ ACM, 01-10-ACA-014, f. 1r.

${ }^{94}$ ACL, P7_M1_P5_C06, sn. [Proceso de Gabriel Rovira apostólico 3-2-1458], f. 10r.

${ }^{95}$ ACM, 01-10-ACA-016, f. 45r.

${ }^{96}$ Ramis 2014, p. 42.

${ }^{97}$ ACM, 01-10-ACA-016, f. 175r.

${ }^{98}$ El seu funcionament, però, no es va desenvolupar completament fins a la fi del segle XVII. Barceló, Urgell 2002. 
cursar estudis superiors s'hagueren de traslladar a centres peninsulars o estrangers. A causa de la inevitabilitat d'haver d'afrontar els perills de la mar, bona part dels estudiants illencs optaren per graduar-se en universitats italianes: no només aquests centres eren més prestigiosos, sinó que tenir un fill amb un títol obtingut en una d'aquestes universitats conferia un cert status a les famílies acomodades. A més, també influïa el cada vegada major interès en la cultura clàssica que s'anava incrementat juntament a la difusió de les idees humanistes ${ }^{99}$. Els canonges del segle $\mathrm{XV}$, continuant amb la tendència observada des de la centúria anterior, també cursaren estudis sobretot a la península Itàlica. Un dels casos més destacats va ser el de l'ardiaca i després bisbe Arnau de Marí i Santacília, que frequientà les universitats de Bolonya i de Pàdua abans de doctorar-se en ambdós Drets a Ferrara el $1418^{100}$. La presència dels canonges mallorquins a Itàlia ajudà a la introducció de les idees humanistes a Mallorca, ja que els prebendats disposaven de les capacitats econòmiques i intel-lectuals necessàries per conèixer i comprendre el nou moviment cultural que s'anava formant a la península ${ }^{101}$.

Altres canonges, en canvi, podien preferir obtenir el grau a l'Estudi General de Lleida. Aquesta institució havia estat fundada el 1300 pel rei Jaume II d'Aragó, essent la primera universitat erigida en els seus regnes. El monarca hauria escollit la ciutat de Lleida com a seu de l'estudi perquè es trobava en un punt equidistant i de fàcil accés des de Catalunya, Aragó i València. D'aquesta manera, Jaume II havia volgut fundar una universitat que servís per cohesionar els seus dominis ${ }^{102}$. Tot $\mathrm{i}$ que la presència de mallorquins en aquesta institució no va ser tan significativa com la dels procedents d'altres regnes de la Corona d'Aragó -especialment valencians, que arribaren a configurar una nació pròpia ${ }^{103}$-, l'Estudi General de Lleida va ser una alternativa per als illencs que no es podien permetre el viatge i la subsistència a Itàlia, a més de resultar més còmode ${ }^{104}$. Qui sembla que va obtenir el seu grau a l'Estudi General de Lleida va ser Gabriel Cerdà que, com s'ha indicat, també era canonge de la catedral d'aquesta diòcesi i, per tant, viatjava amb una certa frequiència a la ciutat. Ara bé, cal tenir present que Cerdà no comptava amb cap grau universitari quan va accedir a cap de les dues prebendes, tot i que ben aviat va aconseguir el batxillerat en Cànons. També el canonge Jaume Miquel Armadans va viatjar en nombroses ocasions a la ciutat del Segre per seguir

\footnotetext{
${ }^{99}$ Ramis 2014, pp. 37-47.

${ }^{100}$ Planas 1997, p. 23.

${ }^{101}$ Barceló, Ensenyat 2013, p. 10.

${ }^{102}$ Pemán 2002, p. 76-82.

${ }^{103}$ Gayà 1950.

${ }^{104}$ Ramis 2014, p. 42.
} 
estudis universitaris entre el 1485 i el 1489, any a partir del qual no tornà a anar-se'n de Mallorca ${ }^{105}$. Malauradament, les fonts no indiquen quin grau va obtenir Armadans, tot i que el més probable és que cursés els estudis de Dret Canònic, àmbit en el qual l'Estudi General de Lleida era molt prestigiós ${ }^{106}$.

Un darrer cas era el dels canonges que cursaven estudis primer a Lleida i que després es traslladaven a una universitat italiana per obtenir-hi el grau corresponent, una pràctica ben documentada ${ }^{107}$. Aquest potser fou el cas de Pedro Ferriz, que es va doctorar en ambdós Drets a la Universitat de Bolonya després d'haver estudiat algun temps a l'Estudi General de Lleida ${ }^{108}$.

\section{CONCLUSIONS}

El coneixement del capítol de Mallorca durant la segona meitat del segle XV ha estat l'objectiu que el present article ha perseguit durant l'exposició. A partir de totes les dades aportades, és possible extreure'n algunes conclusions. Tot i això, cal ser conscient del caràcter limitat d'aquest treball i de la necessitat d'aprofundir en la investigació -fins i tot, arribant directament al nivell de la biografia de cada canonge- per assolir un major coneixement dels actors, tot i que mai podrà ser complet. En qualsevol cas, aquest article constitueix una primera visió de conjunt de tot el capítol catedralici de Mallorca i permet començar a delinear-ne alguns aspectes que, sense cap mena de dubte, seran imprescindibles a l'hora d'elaborar una prosopografia dels prebendats que regiren la catedral mallorquina durant cinquanta anys.

Un dels primers elements a destacar és que s'aporta la nòmina dels setanta-quatre canonges que es varen succeir en el capítol catedralici durant el període estudiat. La identificació dels prebendats és un exercici necessari a partir del qual anar aprofundint en el coneixement dels individus de forma particular i del col-lectiu canonical en el seu conjunt. A més, aquesta onomàstica sistematitza la informació dispersa entre les actes capitulars, els llibres de la Mensa Capitular i el Llibre de Possessoris de la Seu de Mallorca i permet superar les llacunes documentals que s'hi donen. La simple nòmina dels canonges, però, no aporta massa si no és analitzada adequadament i no se n'obtenen alguns resultats procedents del creuament entre diferents fonts documentals.

De fet, un estudi una mica més detallat dels canonges de forma individualitzada permet observar l'interès dels prebendats per l'acumulació de

\footnotetext{
${ }^{105}$ ACM, 2794, sf.

${ }^{106}$ Pemán 2002, pp. 94-95.

${ }^{107}$ Ramis 2014, p. 43.

${ }^{108}$ Escolano 1611, col. 1365. No així Moroni 1844, pp. 196-197.
} 
càrrecs i oficis, el que es traduïa en majors rendes anuals. A aquest efecte, els canonges podien optar tant per ostentar càrrecs dins la mateixa Seu com per fer-ho a fora de l'àmbit catedralici o, fins i tot, de Mallorca. Entre els primers casos, s'observa com els canonges tendeixen a posseir les principals dignitats catedralícies -ardiaca, sagristà, degà-, tot i que només es té constància d'un pagament extraordinari en el cas del deganat. Això no obstant, les dignitats no tenien només valor monetari, sinó també simbòlic i social, de manera que l'ostentació d'aquestes no s'ha d'entendre únicament des del punt de vista material. Tot i això, sobta que dues dignitats -cabiscol i succentor- no fossin posseïdes sistemàticament per canonges. En canvi, sí que els prebendats tingueren molt d'interès en controlar les pabordies, els rèdits de les quals eren bastant substanciosos i, per tant, atractius.

Per altra banda, no sempre els canonges mallorquins buscaven responsabilitats a fora de Mallorca, sinó que, en moltes ocasions, el canonicat insular constituïa un premi o una gràcia per a un servei. Era molt habitual que les prebendes catedralícies fossin utilitzades durant l'Edat Mitjana per afavorir col-laboradors i servidors, especialment per part dels papes, que les concedien en expectativa i fent ús de les denominades "reserves pontifícies" 109. Però també les empraren pel mateix motiu reis i bisbes. Els exemples són molt abundants en aquest aspecte. Potser el cas més destacat sigui el d'Antoni Cerdà, que ja havia ocupats diversos càrrecs a la cort pontifícia abans de ser nomenat canonge de Mallorca ${ }^{110}$. Similar va ser la situació de Bernat Rovira, que també havia fet mèrits a Roma quan fou proveït de la seva canongia. Joan Andreu Sorts ja era canonge de Barcelona quan va accedir a la prebenda mallorquina el 1467 i, molt probablement, Gabriel Valls també ocupava la succentoria de la Capella Reial de Joan II amb anterioritat a la seva designació canonical.

Les principals famílies de l'oligarquia mallorquina tampoc perderen l'oportunitat d'afavorir els seus membres, especialment els fadristerns que destinaven a la carrera eclesiàstica. Aquest fenomen es pot observar amb facilitat mitjançant una senzilla lectura dels llinatges dels canonges, que, en alguns casos, es repeteixen amb una certa assiduïtat -per exemple, Cerdà, Marí, Rovira, com a casos més destacats-. Es va donar, per tant, una oligarquització del capítol catedralici, un fet que es documenta en altres bisbats durant la Baixa Edat Mitjana, i que es va veure afavorit per la normativa episcopal i pontifícia que tendia a restringir l'accés a les canongies a graduats universitaris o a membres de famílies de determinats estaments. L'objectiu d'aquesta restricció

\footnotetext{
${ }^{109}$ Guijarro 2008, p. 273.

${ }^{110}$ Bover 1838 , pp. $70-72$, tot i que amb errors.
} 
era assegurar que els canonges no dependrien únicament de les porcions canonicals per subsistir, però, al mateix temps, també hi podria haver la intenció d'evitar una mescla social dins la institució canonical. Així mateix, el nepotisme va ser una constant. Els canonges intentaren afavorir els seus parents en l'accés a la prebenda, com faria Antoni Cerdà en favor del seu nebot Gabriel, o Gabriel Rovira envers el seu nebot Francesc. Evidentment, com més alta fos la posició en la jerarquia eclesiàstica, més possibilitats d'èxit en aquest aspecte hi havia. Ja Gil Sánchez Muñoz havia promogut la provisió d'una canongia al seu nebot Dionís Sánchez Muñoz. També Arnau de Marí i Santacília actuaria de forma similar en favor d'un presumpte parent homònim.

A més de l'extracció familiar, l'obtenció d'un grau universitari es va convertir en un requisit per accedir a una canongia a la catedral de Mallorca. Com passava en totes les diòcesis, els prebendats mallorquins optaren per graduar-se majoritàriament en Dret Canònic o, en altres casos, en ambdós Drets. Sobta, per altra banda, que la documentació no reculli cap cas ni de graduats en Teologia ni de clergues que s'haguessin conformat únicament amb el grau en Arts i Filosofia, si bé es podria esperar que fossin minoritaris ${ }^{111}$. Els centres d'estudis varen ser, sobretot, les universitats italianes, ja que els mallorquins preferiren obtenir els graus a les prestigioses institucions de la península Itàlica, atenent que havien de realitzar necessàriament un trasllat. Això no obstant, també es documenta la presència de clergues mallorquins a Lleida. Un d'aquests, Gabriel Cerdà, era també canonge en aquesta diòcesi, de manera que aprofità les seves estades a la ciutat del Segre per aconseguir un grau universitari en Dret Canònic. Les motivacions d'altres canonges, com Jaume Miquel Armadans, per estudiar a Lleida en lloc d'una universitat italiana resten encara desconegudes.

Per tant, una primera aproximació a la prosopografia dels canonges mallorquins permet observar que provenien de famílies benestants i que tenien formació universitària, dos elements que comparteixen a grans trets amb altres capítols de la Corona d'Aragó. A més, cal recalcar que aquests dos aspectes jugaven un rol fonamental a l'hora d'accedir a les prebendes, i que les famílies formaven les seves pròpies estratègies de cara a afavorir els seus integrants, arribant a la pràctica de la resignació o la permuta de prebendes. Un estudi més profund de la biografia dels canonges mallorquins permetrà determinar amb major exactitud les relacions -indubtables- entre el capítol i l'oligarquia ciutadana.

${ }^{111}$ Lop 2001, p. 751. 


\section{BIBLIOGRAFIA CITADA}

Agúndez San Miguel, Leticia (2014), Carreras eclesiásticas y redes clientelares en la Castilla bajomedieval: la provisión de beneficios menores en el cabildo de la catedral de Burgos (1456-1470), "Anuario de Estudios Medievales" 44/2, pp. 665-687.

Álvarez Palenzuela, Vicente Ángel (1984), El Cisma de Occidente, Madrid, Rialp.

Barceló Crespí, Maria; Ensenyat Pujol, Gabriel (1996), Ferrando Valentí $i$ la seva família, Barcelona, Publicacions de l'Abadia de Montserrat.

Barceló Crespí, Maria; Ensenyat Pujol, Gabriel (2000), Els nous horitzons culturals a Mallorca al final de l'Edat Mitjana, Palma, Documenta Balear.

Barceló Crespí, Maria; Ensenyat Pujol, Gabriel (2010), Esperandéu Espanyol, un canonge del segle XV amb interessos humanistes $i$ lul-listes, "Bolletí de la Societat Arqueològica Lul·liana" 66, pp. 51-61.

Barceló Crespí, Maria; Ensenyat Pujol, Gabriel (2013), Clergues il·lustrats. Un cercle humanista a l'entorn de la Seu de Mallorca (1450-1550), Palma, Publicacions Catedral de Mallorca.

Barceló Crespí, Maria; Urgell Hernández, Ricard (2002), La Universitat de Mallorca: origen i evolució fins el segle XVIII, a Busqueta i Riu, Joan Josep; Pemán Gavín, Juan (coord.), Les universitats de la Corona d'Aragó, ahir i avui. Estudis històrics, Barcelona, Pòrtic, pp. 157-192.

Bolòs i Masclans, Jordi; Piqué i Badia, Joan Ramon (2008), Les parròquies. Centres espirituals $i$ demarcacions territorials, a Bertran i Roigé, Prim; Fité i Llevot, Francesc (coord.), Arrels cristianes. Presència i significació del cristianisme en la història i la societat de Lleida. Volum II. Temps de consolidació. La baixa Edat Mitjana (segles XIII$X V)$, Lleida, Pagès editors - Bisbat de Lleida, pp. 111-130.

Borau i Morell, Cristina (2003), Els promotors de capelles i retaules a la Barcelona del segle XIV, Barcelona, Fundació Noguera.

Bover de Rosselló, Joaquín María (1838), Memoria biográfica de los mallorquines que se han distinguido en la antigua y moderna literatura, Palma, Imprenta Nacional regentada por D. Juan Guasp.

Campaner y Fuertes, Álvaro (2007), Cronicón Mayoricense, Palma, Sa Nostra.

Cassanyes Roig, Albert (2016), De Mallorca a Nápoles, Lleida y Roma: los viajes del canónigo Gabriel Cerdà (1450-1491), "Historia. Instituciones. Documentos" 43, pp. 99-114.

Colom i Palmer, Mateu (1986), Relació dels inquisidors responsables del tribunal del Sant Ofici a Mallorca i les seves dates d'actuació (1488-1820), a La Inquisició a les Illes Balears. Segles XV al 
XIX, Palma, Conselleria d'Educació i Cultura de les Illes Balears, pp. 33-37.

Colom i Palmer, Mateu (1992), La Inquisició a Mallorca (1488-1578), Barcelona, Curial.

Dameto, Joan; Mut, Vicenç; Alemany, Jeroni (1841), Historia General del Reino de Mallorca escrita por los cronistas don Juan Dameto, don Vicente Mut y don Gerónimo Alemany, vol. III, Palma, Imprenta Nacional á cargo de D. Juan Guasp y Pascual.

Díaz Ibáñez, Jorge (2009), Iglesia y nobleza en la Sevilla bajomedieval, "Anuario de Estudios Medievales" 39/2, pp. 877-931.

Ensenyat Pujol, Gabriel (2012), Humanisme i Renaixement a Mallorca: noves dades, nova periodització, "eHumanista/IVITRA" 1, pp. 99-127.

Escolano i Villalba, Gaspar (1611), Segunda parte de la década primera de la Historia de la Insigne y Coronada Ciudad y Reyno de Valencia, València, Pedro Patricio Mey.

Eubel, Konrad (1914), Hierarchia catholica Medii Aevi, sive Summorum pontificum, S.R.E. cardinalium, ecclesiarum antistitum series ab anno 1431 usque ad annum 1503 perducta e documentis tabularii praesertim Vaticani collecta, digesta, edita per Conradum Eubel, vol. II, Ratisbona, Monasterii, Sumptibus et Typis Librariae Regensbergianae.

Fernández Conde, Francisco Javier (2003), Renacimiento urbano y religiosidad: los cabildos de canónigos, a Las sociedades urbanas en la España medieval, Pamplona, Gobierno de Navarra, pp. 311-352.

Fuente, Vicente de la (1863), España Sagrada, continuada por la Real Academia de la Historia. Tomo XLIX. Tratado LXXXVII. La Santa Iglesia de Tarazona en sus estados antiguo y moderno, Madrid, Imprenta de José Rodríguez.

Gayà Massot, Ramon (1950), Los valencianos en el Estudio General de Léri$d a$, València, Consejo Superior de Investigaciones Científicas, Patronato "José María Quadrado".

Guijarro González, Susana (2008), Jerarquía y redes sociales en la Castilla medieval: la provisión de beneficios eclesiásticos en el cabildo de la catedral de Burgos (1390-1440), "Anuario de Estudios Medievales" 38/1, pp. 271-299.

Iglesias Ortega, Arturo (2010), El cabildo catedralicio de Santiago de Compostela en el siglo XVI: aspectos funcionales y sociológicos de una élite eclesiástica, Santiago de Compostel·la, Universidade de Santiago de Compostela (tesi doctoral).

Llompart Moragues, Gabriel (1975), El llibre català a la casa mallorquina, “Analecta Sacra Tarraconensia” 48, pp. 193-240. 
Lop Otín, María José (2001), El cabildo catedralicio de Toledo en el siglo XV: aspectos institucionales y sociológicos, Madrid, Universidad Complutense de Madrid (tesi doctoral).

Lop Otín, María José (2003), Las catedrales y los cabildos catedralicios de la Corona de Castilla durante la Edad Media: un balance historiográfico, "En la España medieval" 26, pp. 371-404.

Lop Otín, María José (2014), Iglesia y vida urbana. Las ciudades del arzobispado de Toledo a fines del Medioevo, "Edad Media. Revista de Historia" 15, pp. 135-154.

Luis López, Carmelo (2004), El cabildo de la iglesia Catedral de Ávila a fines de la Edad Media, "Espacio, Tiempo y Forma, Serie III, Historia Medieval" 17, pp. 353-369.

Mas i Forners, Antoni (2000), De pagesos a cavallers: l'extracció social i el patrimoni del cardenal Antoni Cerdà i del canonge Gabriel Cerdà (segles XV-XVI), a Barceló Crespí, Maria (coord.), Al tombant de l'edat mitjana. Tradició medieval i cultura humanística, Palma, Institut d'Estudis Baleàrics, pp. 437-450.

Mateu Mairata, Gabriel (1985), Obispos de Mallorca, Palma, Ediciones Cort.

Molina i Figueras, Joan (1999), Arte, devoción y poder en la pintura tardogótica catalana, Múrcia, Universidad de Murcia.

Moroni, Gaetano (1844), Dizionario di erudizione storico-ecclesiastica da S. Pietro ai nostri giorni, vol. XXIV, Venècia, Tipografia Emiliana.

Munsuri Rosado, María Nieves (2006), Perspectiva socio-económica del clero secular en la Valencia del siglo XV, València, Universitat de València (tesi doctoral).

Navarro Espinach, Germán; Villanueva Morte, Concepción (2006-2008), Gil Sánchez Muñoz (1370-1447), el antipapa Clemente VIII. Documentación inédita de los archivos de Teruel, "Revista de Historia Medieval" 15 , pp. 239-254.

Olivares Terol, María José (1997), El obispado de Cartagena-Murcia y su cabildo catedralicio. Formación y evolución en el transcurso de la Edad Media, "Anuario de Estudios Medievales" 27, pp. 1149-1175.

Pemán Gavín, Juan (2002), El marco jurídico e institucional del Estudi General de Lleida (1300-1717), a Busqueta i Riu, Joan Josep; Pemán Gavín, Juan (coord.), Les universitats de la Corona d'Aragó, ahir i avui. Estudis històrics, Barcelona, Pòrtic, pp. 75-115.

Pérez Rodríguez, Francisco Javier; González Vázquez, Marta (1993), Aproximación al estudio de las relaciones familiares y de poder en una institución eclesiástica: el cabildo compostelano en los siglos XII y XIII, "Hispania. Revista española de historia" 53/185, pp. 1091-1098. 
Planas Rosselló, Antonio (1997), Los juristas mallorquines del siglo XV, "Memòries de l'Acadèmia Mallorquina d'Estudis Genealògics, Heràldics i Històrics" 7, pp. 23-59.

Quiroga Conrado, Magdalena de (2009), La emblemática caballeresca en la Mallorca del Renacimiento siglos XV-XVI: las cimeras y las divisas, "Memòries de la Reial Acadèmia Mallorquina d'Estudis Genealògics, Heràldics i Històrics" 19, pp. 29-96.

Ramis Barceló, Rafael (2014), Peregrinatio academica: legistas y canonistas de la Corona de Aragón en las universidades italianas durante el Renacimiento, "Miscellanea Historico-iuridica" 13, pp. 35-66.

Rius i Serra, José (1927), Catalanes y aragoneses en la corte de Calixto III, "Analecta Sacra Tarraconensia" 3, pp. 193-330.

Rosselló Lliteras, Juan (1978), Estratificación social del clero de Mallorca, "Bolletí de la Societat Arqueològica Lul-liana" 36, pp. 189-208.

Sánchez Herrero, José (1976), Vida y costumbres de los componentes del Cabildo Catedral de Palencia a finales del siglo XV, "Historia. Instituciones. Documentos" 3, pp. 485-532.

Santamaría Lancho, Miguel (1982), La organización de la gestión económica del cabildo catedralicio de Segovia (siglos XIII-XIV), "En la España medieval" 3, pp. 505-540.

Santamaría Lancho, Miguel (1985), La explotación económica del patrimonio urbano del Cabildo catedralicio de Segovia en el siglo XIV, "En la España medieval" 6,pp. 671-700.

Santamaría Lancho, Miguel (1990), El cabildo catedralicio de Segovia como aparato de poder en el sistema político urbano durante el siglo $X V$, "Studia historica. Historia medieval" 8, pp. 47-78.

Sanz Sancho, Iluminado (2000), El cabildo catedralicio de Córdoba en la Edad Media, "En la España medieval" 23, pp. 189-264.

Serra i Ferragut, Bonaventura (1774), Recreaciones eruditas, BMM, ms. 470, vol. I.

Serra i Ferragut, Bonaventura (1815), Recreaciones eruditas, BMM, ms. 473, vol. IV.

Sureda i Jubany, Marc (2009), La catedral i la ciutat: dels orígens medievals al segle XVIII, a Església, societat i poder a Girona. Segles XVI-XX, Girona, Ajuntament de Girona, pp. 37-92.

Terré i Vila, Mercè; Baulies i Bochaca, Núria (1993), Estudi de les pabordies de la Seu de Lleida (1467-1468), a Bolòs i Masclans, Jordi (coord.), Paisatge i societat a la Plana de Lleida a l'Edat Mitjana, Lleida, Universitat de Lleida, pp. 115-150.

Vidal Rettich, José Alfredo (1985), El clero de Mallorca con cura de almas al introducirse la reforma tridentina, "Bolletí de la Societat Arqueològica Lul-liana" 41, pp. 269-278. 
Vigil Montes, Néstor (2011), Las actas del cabildo catedralicio como fuente para la historia del poder en una urbe medieval. El caso de Oviedo en el siglo $X V$, a Solórzano Telechea, Jesús Ángel; Arízaga Bolúmburu, Beatriz (coord.), La gobernanza de la ciudad europea en la Edad Media, Logroño, Instituto de Estudios Riojanos, pp. 549-565.

Villanueva Astengo, Jaime (1851), Viage literario a las iglesias de España. Tomo XXI. Viage á Mallorca, Madrid, Real Academia de la Historia. Xamena Fiol, Pere; Riera Montserrat, Francesc (1986), Història de l'Església a Mallorca, Palma, Editorial Moll.

Fecha de recepción del artículo: abril 2016

Fecha de aceptación y versión final: agosto 2016 